\title{
今Mv
}

\section{Mechanical ventilation modes utilization. An international survey of clinicians}

Ehab G. Daoud MD ${ }^{1}$, Kimiyo Yamasaki RRT ${ }^{2}$, Ronald R. Sanderson RRT ${ }^{3}$, Mia Shokry ${ }^{4}$

DOI: https://doi.org/10.53097/JMV.10031

Cite: Daoud EG, Yamasaki K, Sanderson R, Shokry M. Mechanical ventilation modes utilization. An international survey of clinicians. J Mech Vent 2021; 2(3):105-111.

\begin{abstract}
:
Background:

There has been an exponential increase in modes of mechanical ventilation over the last couple decades. With this increase, there has been a paucity of evidence of which mode is superior to others or much guidance to use a mode in different disease status causing respiratory failure.

Methods:

An international survey of six questions was posted on the "society of mechanical ventilation" website and advertised on social media over the period of four months. This is a descriptive study; results are presented in two different ways. First as the total modes used and secondly, per the geographical areas as the preferred mode, mode used mostly in ARDS, COPD, and Spontaneous weaning trials.

Results:

Conventional older modes, Volume-controlled and Pressure-controlled ventilation were used significantly more in general and in different disease states irrespective of geographical location. Four other modes were used almost equally in all disease states irrespective of geographical location. Pressure support ventilation was the most common mode used during the spontaneous breathing trial.

\section{Conclusion:}

There was large heterogenicity of modes used between clinicians in general, in different disease states and in between different international geographical locations. Mechanical ventilation modes utilization varies widely and remains a personal preference with no consensus between clinicians globally.
\end{abstract}

Keywords: Modes of mechanical ventilation, ARDS, COPD, SBT, Survey

Authors

1. Ehab G Daoud, MD, FACP, FCCP. Associated professor of Medicine, John A Burns School of Medicine, Hawaii, USA and director of respiratory care program, Kapiolani Community College, Hawaii, USA

2. Yamasaki K. RRT, Adventist Health Castle Medical Center, Hawaii, USA

3. Ronald R. Sanderson, RRT, DrPH, AE-C. Respiratory center of Hawaii. Hawaii, USA

4. Mia Shokry, Pre-med student, University of Southern California, California, USA

Corresponding author: ehab_daoud@hotmail.com

Conflict of interest/Disclosures: None

Funding: None 


\section{Introduction}

Since the popularization of positive pressure ventilators in the middle of the last century, there has been exponential growth and improvement in the technology and modes available today. Compared to five decades ago, we now have more than 174 modes as opposed to only three back then. ${ }^{1}$ This plus the lack of strong evidence of superiority of one mode over the others in different disease states, the choice of a mode has remained to be personal familiarity and institutional preferences. ${ }^{2}$ In addition, the brand, model, and modes of the ventilators used around the world are affected by availability, marketing, and financial resources.

The proliferation of names of the modes had has added confusion to the mode utilization. This problem that has been addressed by some in creating a general taxonomy for modes of mechanical ventilation. ${ }^{3}$

\section{Materials and Methods}

We designed a six questions questionnaire and posted on the "Society of Mechanical Ventilation" website and advertised for it in the monthly newsletter and in different social media platforms. The survey was active for four months and closed once we had collected one hundred surveys. The questionnaire was anonymous and included the country of practice, names of the ventilator manufacturer, the mode of preferred use by the surveyed in general, the mode of their preferred use in the acute respiratory distress syndrome (ARDS), chronic obstructive lung disease (COPD) and to perform a spontaneous breathing trial (SBT). No IRB application was filled given the survey was anonymous with no subject or institutional identifiers.

We analyzed the results in two distinct styles to assess for any variance in responses. We first grouped the responses from all

the participants collectively based on the initially chosen modes. Subsequently, we subgrouped the responses after classifying participants based on three geographical categories into 3 regions: 1) North and South Americas, 2) Europe and Africa, and 3) Asia and Australia.

\section{Results}

One hundred participants from thirty-three countries filled the survey (40/100 from the USA). 52/100 from North and South America, 24/100 from Europe and Africa, and 24/100 from Asia and Australia.

Five ventilator companies counted for $83 \%$ of ventilator used, while six other manufacturers counted for the other 13\%. Most of those surveyed had at least two different ventilator manufacturers at their institutions. The online accompanying supplement shows the breakdown of countries and ventilator manufacturers.

Figures 1-3 summarize the results of the survey. There is wide variation and heterogenicity of the choice of the mode of mechanical ventilation used. However, the conventional modes of ventilation like the Volume-Controlled (VCV) and Pressure-Controlled (PCV) modes still dominate as the most used modes.

The disease state of ARDS vs. COPD altered the modes used with more PCV and Airway Pressure Release Ventilation (APRV) in the former compared with VCV in the latter. Most of the other modes: Pressure Regulated Volume Control (PRVC), ASV (Adaptive Support Ventilation), Synchronized Intermittent Mandatory Ventilation (SIMV-VC and SIMVPC) remained not much changed. Pressure Support Ventilation (PSV) was the dominant mode used for the spontaneous breathing trials compared to all other modes.

\section{Discussion}

This international survey study shows wide variation in the practice of mechanical ventilation between clinicians in different geographical locations. Our results show that most of the clinicians surveyed use more than one ventilator from different companies. And five ventilator manufacturers made up more than $80 \%$ of ventilators used in the survey.

Our study is the first one to address this issue all over the world, not just in one country or specific region. Our results are in agreement with other studies addressing the same issue and with similar results. ${ }^{2,4,5}$ 

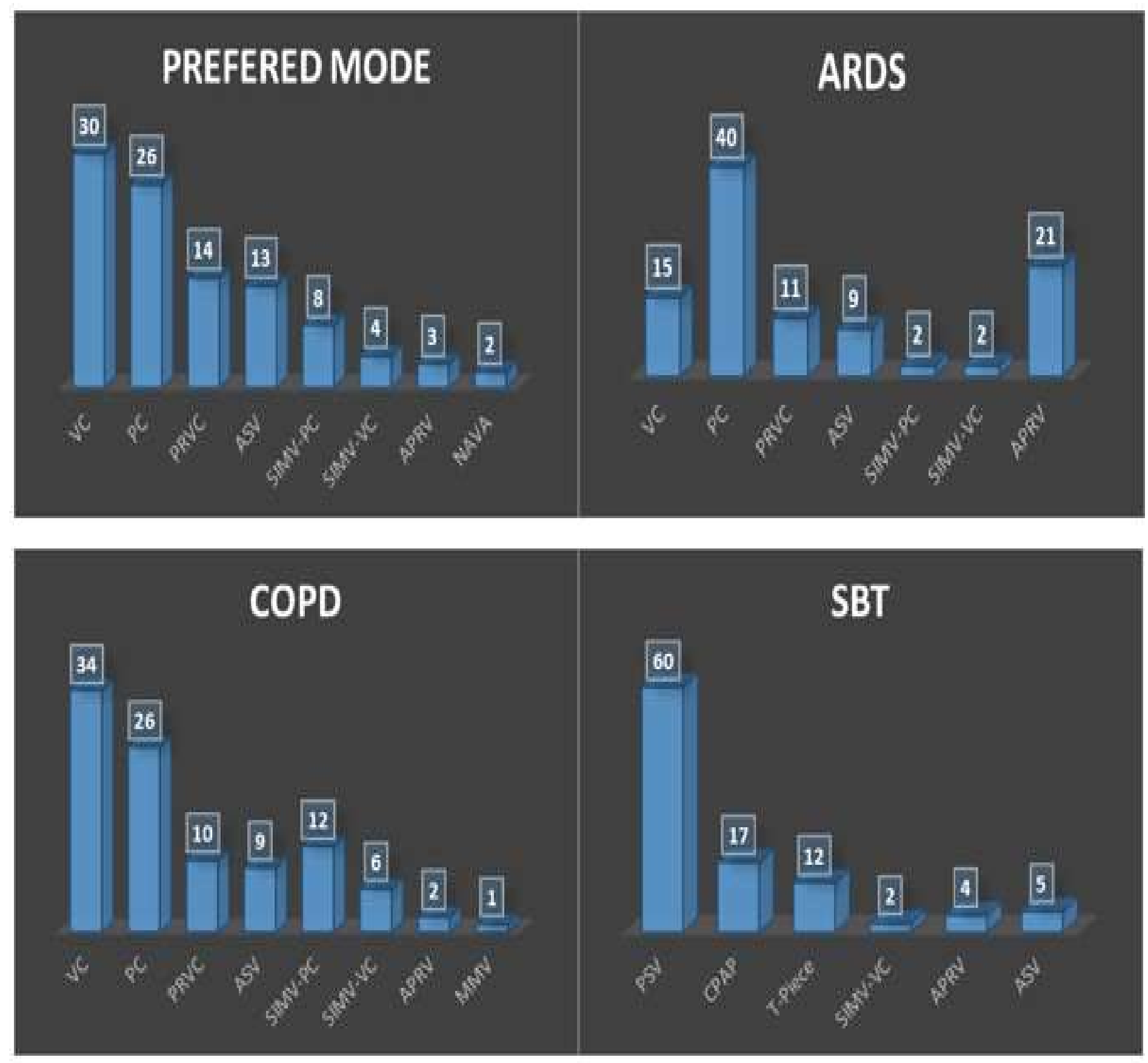

Figure 1: Total numbers of modes chosen by surveyed clinicians as their preferred mode, modes they use in ARDS, COPD, SBT. APRV: Airway pressure release ventilation, ARDS: Acute respiratory distress syndrome, ASV: Adaptive support ventilation, CPAP: Continuous positive airway pressure, COPD: Chronic obstructive pulmonary disease, MMV: Mandatory minute ventilation, NAVA: Neurally adjusted ventilatory assist, PC: Pressure controlled ventilation, PRVC: Pressure regulated volume control, SBT: Spontaneous breathing trial, SIMV-PC: Synchronized intermittent mandatory ventilation-pressure control, SIMV-VC: Synchronized intermittent mandatory ventilation-volume control, VC: Volume controlled ventilation. 
A

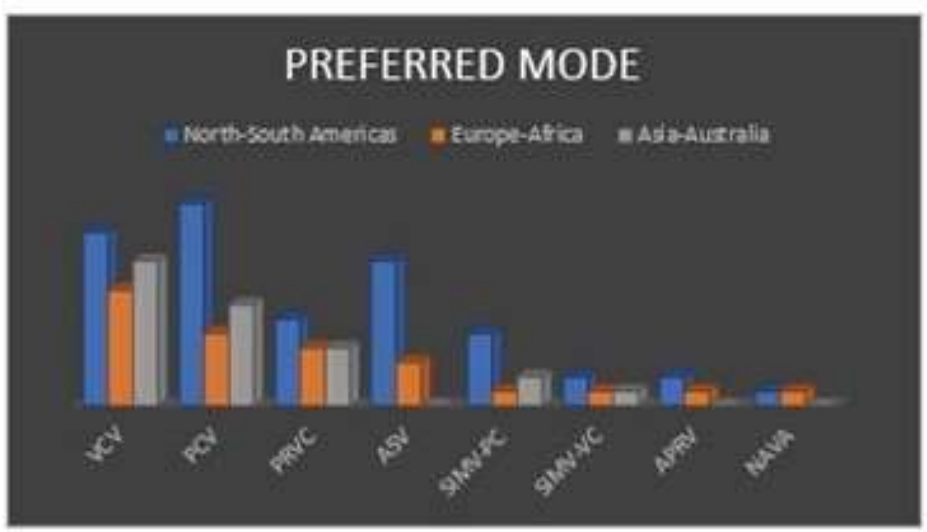

\begin{tabular}{|l|c|c|c|c|c|c|c|c|}
\hline & VCV & PCV & PRVC & ASV & $\begin{array}{l}\text { SIMV- } \\
\text { PC }\end{array}$ & $\begin{array}{l}\text { SINV } \\
\text { VC }\end{array}$ & APRV & NAVA \\
\hline $\begin{array}{l}\text { North- } \\
\text { South } \\
\text { Americas }\end{array}$ & 12 & 14 & 6 & 10 & 5 & 2 & 2 & 1 \\
\hline $\begin{array}{l}\text { Europe- } \\
\text { Africa }\end{array}$ & 8 & 5 & 4 & 3 & 1 & 1 & 1 & 1 \\
\hline $\begin{array}{l}\text { Asia- } \\
\text { Australia }\end{array}$ & 10 & 7 & 4 & 0 & 2 & 1 & 0 & 0 \\
\hline Total & 30 & 26 & 14 & 13 & 8 & 4 & 3 & 2 \\
\hline
\end{tabular}

B

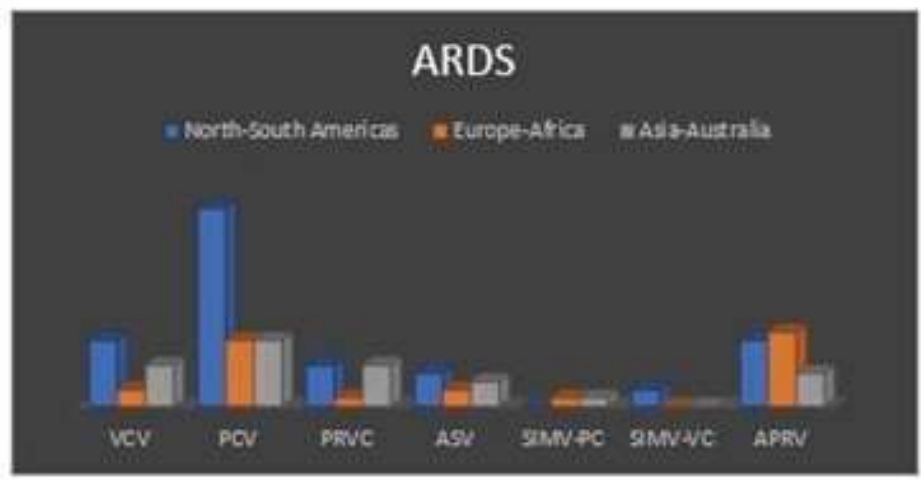

\begin{tabular}{|l|c|c|c|c|c|c|c|}
\hline & VCV & PCV & PRVC & ASV & $\begin{array}{l}\text { SMNV- } \\
\text { PC }\end{array}$ & $\begin{array}{l}\text { SMN- } \\
\text { VC }\end{array}$ & APRV \\
\hline $\begin{array}{l}\text { North- } \\
\text { South } \\
\text { Americas }\end{array}$ & 8 & 24 & 5 & 4 & 0 & 2 & 8 \\
\hline $\begin{array}{l}\text { Europe- } \\
\text { Africa }\end{array}$ & 2 & 8 & 1 & 2 & 1 & 0 & 9 \\
\hline $\begin{array}{l}\text { Atria } \\
\text { Australia }\end{array}$ & 5 & 8 & 5 & 3 & 1 & 0 & 4 \\
\hline Total & 15 & 40 & 11 & 9 & 2 & 2 & 21 \\
\hline
\end{tabular}

C

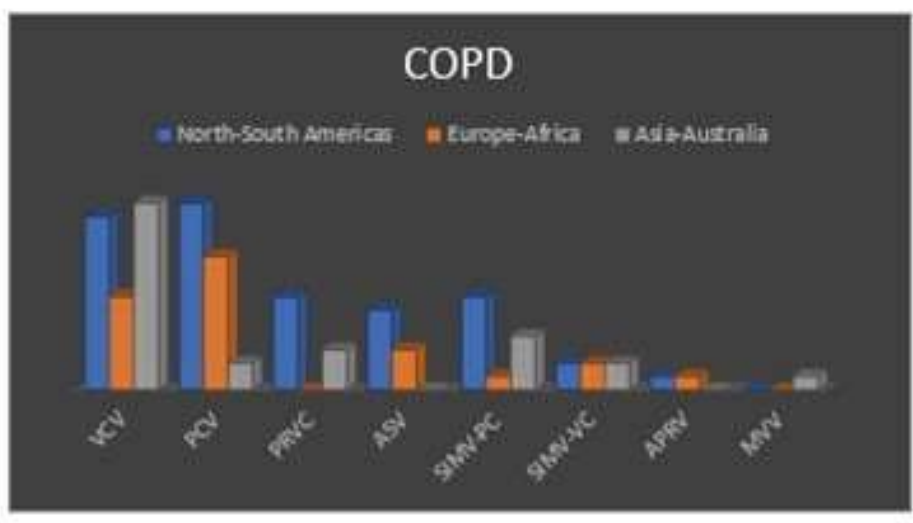

\begin{tabular}{|l|c|c|c|c|c|c|c|c|}
\hline & VCV & PCV & PRVC & ASV & $\begin{array}{l}\text { SMN- } \\
\text { PC }\end{array}$ & $\begin{array}{l}\text { SNN- } \\
\text { VC }\end{array}$ & APRV & MNV \\
\hline $\begin{array}{l}\text { North- } \\
\text { South } \\
\text { Americas }\end{array}$ & 13 & 14 & 7 & 6 & 7 & 2 & 1 & 0 \\
\hline $\begin{array}{l}\text { Europe- } \\
\text { Africa }\end{array}$ & 7 & 10 & 0 & 3 & 1 & 2 & 1 & 0 \\
\hline $\begin{array}{l}\text { Asia- } \\
\text { Autralia }\end{array}$ & 14 & 2 & 3 & 0 & 4 & 2 & 0 & 1 \\
\hline Total & 34 & 26 & 10 & 9 & 12 & 6 & 2 & 1 \\
\hline
\end{tabular}

D

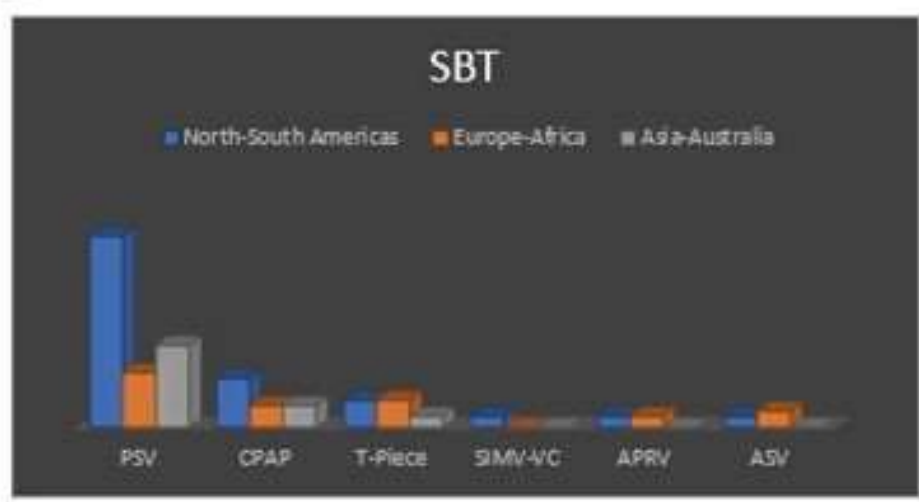

\begin{tabular}{|l|c|c|c|c|c|c|}
\hline & PSV & CPAP & T-Piece & $\begin{array}{l}\text { SINV- } \\
\text { VC }\end{array}$ & APRV & ASV \\
\hline $\begin{array}{l}\text { North-South } \\
\text { Americas }\end{array}$ & 35 & 9 & 5 & 2 & 2 & 2 \\
\hline $\begin{array}{l}\text { Europe- } \\
\text { Africa }\end{array}$ & 10 & 4 & 5 & 0 & 2 & 3 \\
\hline $\begin{array}{l}\text { Aria- } \\
\text { Australia }\end{array}$ & 15 & 4 & 2 & 0 & 0 & 0 \\
\hline Total & 60 & 17 & 12 & 2 & 4 & 5 \\
\hline
\end{tabular}

Figure 2: Total number of modes chosen by surveyed clinicians as their preferred mode, modes they use in ARDS, COPD, SBT according to their geographical location. ARDS: Acute respiratory distress syndrome, ASV: Adaptive support ventilation, CPAP: Continuous positive airway pressure, COPD: Chronic obstructive pulmonary disease, MMV: Mandatory minute ventilation, NAVA: Neurally adjusted ventilatory assist, PC: Pressure controlled ventilation, PRVC: Pressure regulated volume control, SBT: Spontaneous breathing trial, SIMV-PC: Synchronized intermittent mandatory ventilation-pressure control, SIMV-VC: Synchronized intermittent mandatory ventilation-volume control, VC: Volume controlled ventilation. 
A

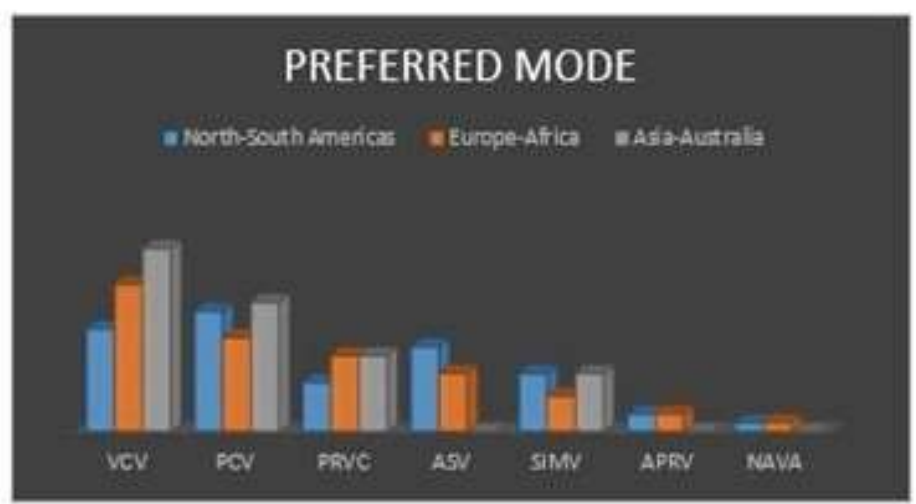

\begin{tabular}{|l|l|l|l|l|l|l|l|}
\hline & VCV & PCV & PRVC & ASV & SIMV & APRV & NAVA \\
\hline $\begin{array}{l}\text { North- } \\
\text { South } \\
\text { Americas }\end{array}$ & $23 \%$ & $27 \%$ & $11 \%$ & $19 \%$ & $13 \%$ & $4 \%$ & $2 \%$ \\
\hline $\begin{array}{l}\text { Europe- } \\
\text { Africa }\end{array}$ & $33 \%$ & $21 \%$ & $17 \%$ & $13 \%$ & $8 \%$ & $4 \%$ & $2 \%$ \\
\hline $\begin{array}{l}\text { Asia- } \\
\text { Australia }\end{array}$ & $41 \%$ & $29 \%$ & $17 \%$ & 0 & $13 \%$ & 0 & 0 \\
\hline
\end{tabular}

B

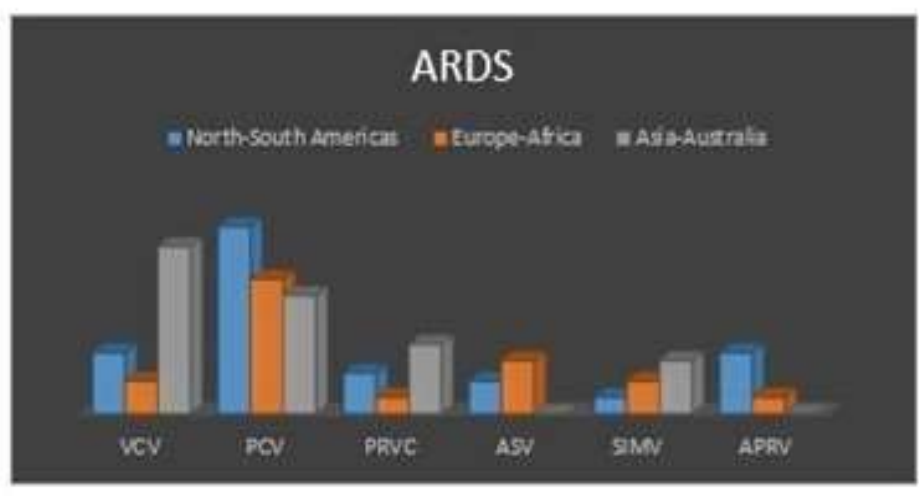

\begin{tabular}{|l|c|c|c|c|c|c|}
\hline & VCV & PCV & PRVC & ASV & SIMV & APRV \\
\hline $\begin{array}{l}\text { North-South } \\
\text { Americas }\end{array}$ & $15 \%$ & $46 \%$ & $10 \%$ & $8 \%$ & $4 \%$ & $15 \%$ \\
\hline $\begin{array}{l}\text { Europe- } \\
\text { Africa }\end{array}$ & $8 \%$ & $33 \%$ & $4 \%$ & $13 \%$ & $8 \%$ & $4 \%$ \\
\hline $\begin{array}{l}\text { Asia- } \\
\text { Australia }\end{array}$ & $41 \%$ & $29 \%$ & $17 \%$ & 0 & $13 \%$ & 0 \\
\hline
\end{tabular}

C

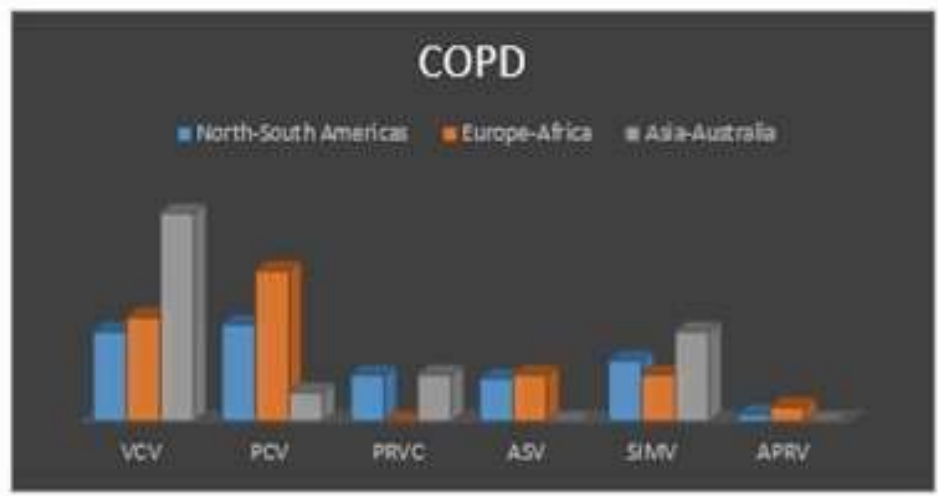

\begin{tabular}{|l|c|c|c|c|c|c|}
\hline & VCV & PCV & PRVC & ASV & SIMV & APRV \\
\hline $\begin{array}{l}\text { North-South } \\
\text { Americas }\end{array}$ & $25 \%$ & $27 \%$ & $13 \%$ & $12 \%$ & $17 \%$ & $2 \%$ \\
\hline $\begin{array}{l}\text { Europe- } \\
\text { Africa }\end{array}$ & $29 \%$ & $42 \%$ & $0 \%$ & $13 \%$ & $13 \%$ & $4 \%$ \\
\hline $\begin{array}{l}\text { Asia- } \\
\text { Australia }\end{array}$ & $58 \%$ & $8 \%$ & $13 \%$ & 0 & $25 \%$ & 0 \\
\hline
\end{tabular}

D

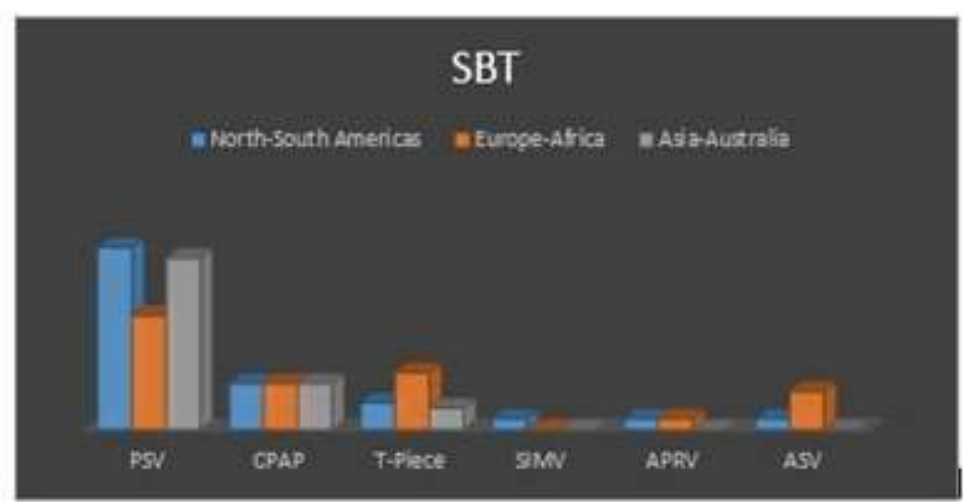

\begin{tabular}{|l|c|c|c|c|c|c|}
\hline & PSV & CPAP & $\begin{array}{c}\text { T- } \\
\text { Piece }\end{array}$ & SIMV & APRV & ASV \\
\hline $\begin{array}{l}\text { North-South } \\
\text { Americas }\end{array}$ & $67 \%$ & $17 \%$ & $10 \%$ & $4 \%$ & $4 \%$ & $4 \%$ \\
\hline Europe-Africa & $42 \%$ & $17 \%$ & $21 \%$ & 0 & $4 \%$ & $14 \%$ \\
\hline Asia-Australia & $63 \%$ & $17 \%$ & $8 \%$ & 0 & 0 & 0 \\
\hline
\end{tabular}

Figure 3: Percentage of the number of modes chosen by surveyed clinicians as their preferred mode, modes they use in ARDS, COPD, SBT according to their geographical location. ARDS: Acute respiratory distress syndrome, ASV: Adaptive support ventilation, CPAP: Continuous positive airway pressure, COPD: Chronic obstructive pulmonary disease, MMV: Mandatory minute ventilation, NAVA: Neurally adjusted ventilatory assist, PC: Pressure controlled ventilation, PRVC: Pressure regulated volume control, SBT: Spontaneous breathing trial, SIMV: Synchronized intermittent mandatory ventilation, VC: Volume controlled ventilation. 
Those findings are expected and understandable given the vast numbers of commercially available modes nowadays ${ }^{1}$ and the paucity of studies and evidence that support a major superiority of some modes over the others. Even in the conventional older modes like Volume and Pressure controlled modes, there are no evidence to support the use of one over the other. ${ }^{6,7}$ There are few studies that suggest the superiority of APRV in ARDS ${ }^{8,9}$ which might explain the spike of use of APRV in ARDS (figure 1\&2).

PSV has shown to be superior to other modes used for the spontaneous breathing trial and weaning off mechanical ventilation. ${ }^{10,11}$ ASV has also shown some superiority above other modes especially in the weaning process. ${ }^{12,13}$

\section{Limitations}

Our study has some limitations, the low number of surveyed clinicians that made performing statistical analysis a difficult task and thus we are describing and presenting our results in a descriptive way.

Additionally, the uneven number between geographical locations with North-South Americas made up more than half of the numbers and double the number from Europe-Africa, and Asia-Australia.

We did not collect information about the clinical experience of those surveyed. Despite those limitations, our study adds some information that have not been studied or validated before.

This data was collected using a convenience sample and as such has some notable weaknesses. First, the only respondents were those visiting the website or associated social media announcements. Second, those who had the interest and time to respond may have different choice of mode practices than those who did not. Third, mode responses were limited by the brand and model of the ventilators in use in a wide spectrum of locations. For example, comparison of VCV and PCV to ASV must be taken in context that nearly all ventilators have VCV and PCV where only one ventilator company sells ventilators with ASV. The same is the case with NAVA and perhaps to some degree APRV.

\section{Conclusion}

There is wide variation of mechanical ventilation modes utilization globally. More comparative studies are needed to guide clinicians on better use of the available modes.

\section{References}

1. Mireles-Cabodevila E, Hatipoğlu U, Chatburn RL. A rational framework for selecting modes of ventilation. Respir Care 2013; 58(2):348-366.

2. Esteban A, Anzueto A, Alía I, et al. How is mechanical ventilation employed in the intensive care unit? An international utilization review. Am J Respir Crit Care Med 2000; 161(5):1450-1458.

3. Chatburn RL, El-Khatib M, Mireles-Cabodevila E. A taxonomy for mechanical ventilation: 10 fundamental maxims. Respir Care 2014; 59(11):1747-1763.

4. Jabaley CS, Groff RF, Sharifpour M, et al. Modes of mechanical ventilation vary between hospitals and intensive care units within a university healthcare system: a retrospective observational study. BMC Res Notes 2018; 11(1):425.

5. Chung KK, Rhie RY, Lundy JB, et al. A Survey of Mechanical Ventilator Practices Across Burn Centers in North America. J Burn Care Res 2016; 37(2):e131-9.

6. Campbell RS, Davis BR. Pressure-controlled versus volume-controlled ventilation: does it matter? Respir Care $2002 ; 47(4): 416-424$.

7. Chacko B, Peter JV, Tharyan P, et al. Pressure-controlled versus volume-controlled ventilation for acute respiratory failure due to acute lung injury (ALI) or acute respiratory distress syndrome (ARDS). Cochrane Database of Systematic Reviews 2015; Issue 1. Art. No.: CD008807.

8. Zhong X, Wu Q, Yang H, et al. Airway pressure release ventilation versus low tidal volume ventilation for patients with acute respiratory distress syndrome/acute lung injury: a meta-analysis of randomized clinical trials. Ann Transl Med 2020; 8(24):1641.

9. Carsetti A, Damiani E, Domizi R, et al. Airway pressure release ventilation during acute hypoxemic respiratory failure: a systematic review and meta-analysis of randomized controlled trials. Ann Intensive Care 2019; 9(1):44.

10. Brochard L, Rauss A, Benito S, et al. Comparison of three methods of gradual withdrawal from ventilatory support during weaning from mechanical ventilation. Am J Respir Crit Care Med 1994; 150(4):896-903. 
11. Alía I, \& Esteban A. Weaning from mechanical ventilation. Critical care 2000; 4(2):72-80.

12. Wheatley D, Young, K. Adaptive support ventilation.

What is it? Beneficial or not? J Mech Vent 2020; 2(1):34-44.

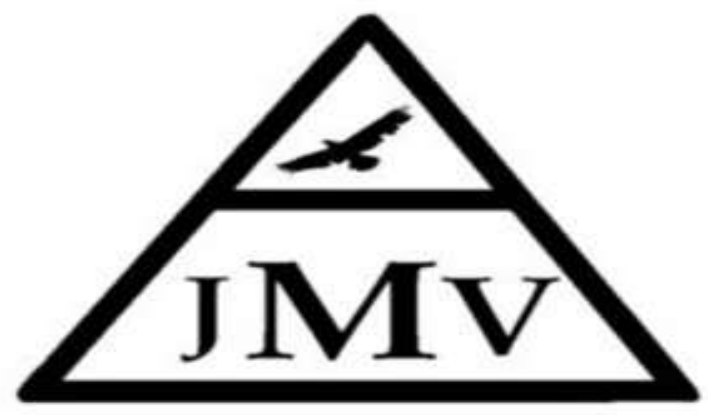

Journal of Mechanical Ventilation

Submit a manuscript

https://www.journalmechanicalventilation .com/submit-a-manuscript/
13. Kirakli C, Ozdemir I, Ucar ZZ, et al. European Respiratory Journal $2011 ; 38: 774-780$.

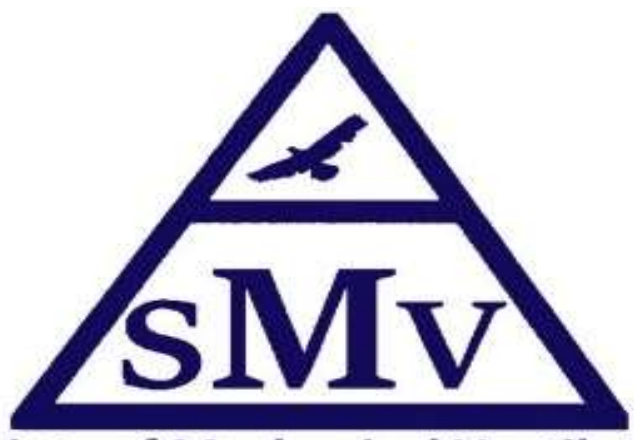

Society of Mechanical Ventilation

Free membership

https://societymechanicalventilation.org /membership/ 